\title{
Bacteriological profile and their antimicrobial susceptibility pattern in central venous catheter tip culture
}

\author{
Sapkota $\mathrm{J}^{1}$, Mishra $\mathrm{B}^{1}$, Jha $\mathrm{B}^{1}$, Sharma $\mathrm{M}^{1}$ \\ ${ }^{I}$ Department of Microbiology, Kathmandu Medical College Teaching Hospital, Sinamangal Kathmandu, Nepal
}

\section{Keywords: \\ Acenitobacter; Antibiotic; \\ Catheter; \\ Colonization; \\ Sensitivity; \\ Staphylococcus;}

\begin{abstract}
Background: Bacterial colonization of central venous catheter carries risk of developing catheter-related blood stream infections. The purpose of this study is to find out the frequency of colonization of by different bacterial pathogens and their antibiotic sensitivity pattern..

Materials and Methods: A total of 53 tip were received in one-year duration for culture and antibiotic sensitivity pattern. The isolated organisms were identified by standard microbiological procedure and subjected to antimicrobial sensitivity.

Results: Out of 53 tip sent for culture and sensitivity, $21(39.6 \%)$ showed significant growth. Out of 21 culture positive $52.3 \%$ were gram negative bacilli, $33.3 \%$ were gram positive cocci, $4.8 \%$ were Candida spp. Acenitobacter baumannii and Staphylococcus aureus were frequent pathogens isolated. Gram negative bacteria were less sensitive to antibiotics whereas gram positive bacteria were sensitive to Vancomycin.
\end{abstract}

Conclusion: Though various organisms were isolated as colonizer of CVC, Acenitobacter baumannii is the most common colonizer. Antibiotic resistance has already emerged and represents a major problem.

\section{INTRODUCTION}

Central venous access is commonly performed in care of critically ill patient to receive fluid and medicine. However, this routine procedure is not immune to complications. ${ }^{1}$ They act as portal of entry of bacteria that colonize the skin adjacent to entry point or may serve as foreign bodies that

\section{Correspondence:}

Dr Jyotshna Sapkota, MBBS, M.D

Lecturer, Department of Microbiology,

Kathmandu Medical College Teaching Hospital,

Sinamangal Kathmandu, Nepal.Email: 21jyots@gmail.com harbors micro colonies, leading to catheter related blood stream infections (CRBSI). ${ }^{2}$

CRBSI is the most common cause of health care- associated infection to the blood stream. ${ }^{3}$ Several studies have shown the increase in risk of bacteremia and sepsis following central venous catheter (CVC) insertion.

This study aims to find the incidence of culture positive CVC tip, pattern of organisms isolated and their antibiotic sensitivity pattern. This, we hope, will serve as a guide in 
Table 1: Distribution of isolated bacteria

\begin{tabular}{lc}
\hline \multicolumn{1}{c}{ Microorganism } & Number of isolates (\%) \\
\hline Acenitobacter baumannii & $6(29 \%)$ \\
\hline Staph. aureus & $4(19 \%)$ \\
\hline Klebsiella pneumonia & $3(14 \%)$ \\
\hline $\begin{array}{l}\text { Coagulase negative staph. } \\
\text { Species (CONS) }\end{array}$ & $3(14 \%)$ \\
\hline Escherichia coli & $1(5)$ \\
\hline Citrobacter freundii & $1(5 \%)$ \\
\hline
\end{tabular}

selection of appropriate antimicrobial agents for prophylaxis and empirical therapy of CRBSI.

\section{MATERIALS AND METHODS}

This study was done in Kathmandu Medical College Teaching Hospital, Kathmandu, Nepal over the period of one year from January 2016 to December 2016. All the central venous catheter tip sent for culture and antibiotic sensitivity in microbiology laboratory of Kathmandu Medical College were included in this study. A total of $53 \mathrm{CVC}$ tips were received in microbiology laboratory over the study period.

Extra luminal Maki's roll plate method was used for processing of catheter tip. Using sterile forceps, the catheter tip was removed from transport tube and laid on Blood agar plate. The tip was rolled back and forth across the entire surface of blood ager plate using sterile forceps and exerting slight downward pressure and incubated aerobically at $37^{\circ}$ C. ${ }^{4,5}$

Agar plates were examined at 24 hours, 48 hours and 72 hours. Significant growth was defined as $>=15$ colony forming unit. Significant colonies were further processed. Organisms were identified according to colony morphology, gram staining and biochemical tests. Antibiotic sensitivity test were done by Kirby Bauer disk diffusion technique as recommended by Clinical Laboratory Standards Institute (CLSI).Statistical analysis was performed using Microsoft Excel.

\section{RESULTS}

A total number of 53 samples were sent to our microbiology laboratory for culture and sensitivity during study period. Out of 53 samples, 21 (39.6\%) showed significant growth of organism. Remaining samples either had no organism grown or had insignificant growth.

Out of 53 samples submitted for culture and antibiotic susceptibility, 21 (39.6\%) showed the significant growth. In our study $52.3 \%$ of pathogens isolated were gram negative bacilli, 33.3\% were gram positive cocci. $9.6 \%$ were multiple growth and $4.8 \%$ were Candida albicans. Acenitobacter baumannii was the most common organism isolated followed by Staph. aureus and Klebsiella pneumoniae. Distribution of isolated bacteria is shown in Table 1. Among these 18 isolates were tested for antibiotic susceptibility pattern. The details of the antimicrobial susceptibility pattern of overall microorganisms are shown in table 2.

\section{DISCUSSION}

Central venous catheter is frequently used in ICU settings, however their colonization with different types of organism increases the hospital stay and mortality in these patients. Colonization of $\mathrm{CVC}$ with microorganism is one of the main risk factor for occurrence of CRBSI. Isolation of microorganisms from CVC segment indicates the colonization of catheter itself. $^{2}$

The incidence rate of central line catheter colonization ranges from $18.3 \%$ to $78 \%$ in different studies. ${ }^{6-10}$ our study showed the colonization rate to be $39.6 \%$.

Table 2: Antimicrobial susceptibility pattern of microorganism

\begin{tabular}{lllll}
\hline \multicolumn{1}{c}{ Antimicrobials } & Number of isolates tested & $\begin{array}{c}\text { Number of sensitive } \\
\text { isolates (\%) }\end{array}$ & $\begin{array}{c}\text { Number of intermediate } \\
\text { isolates (\%) }\end{array}$ & $\begin{array}{c}\text { Number of resistant } \\
\text { isolates (\%) }\end{array}$ \\
\hline Amikacin & 18 & $7(39)$ & $1(5)$ & $10(56)$ \\
\hline Ampicillin & 18 & $0(0)$ & 0 & $18(100)$ \\
\hline Cefixime & 18 & $0(0)$ & 0 & $18(100)$ \\
\hline Ceftriaxone & 17 & $3(18)$ & 0 & $7(82)$ \\
\hline chloramphenicol & 15 & $8(53)$ & 0 & $14(87.5)$ \\
\hline Ciprofloxacin & 16 & $2(12.5)$ & 0 & $6(86)$ \\
\hline Cloxacillin & 7 & $1(14)$ & 0 & $14(100)$ \\
\hline Co-trimoxazole & 14 & 0 & 0 & 0 \\
\hline Colistin & 6 & $6(100)$ & 0 & $11(73)$ \\
\hline Gentamicin & 15 & $4(27)$ & 0 & $4(50)$ \\
\hline Imipenem & 8 & $4(50)$ & 0 & 0 \\
\hline Linezolid & 5 & $5(100)$ & 0 & $4(50)$ \\
\hline Piperacillin-tazobactum & 8 & $4(50)$ & 0 & 0 \\
\hline Vancomycin & 7 & $7(100)$ & 0 & \\
\hline
\end{tabular}


In most of the studies Gram positive cocci were the predominant colonizer of CVC. . $^{5-9}$ however our study showed the predominant organism to be gram negative bacilli, which is consistent with some of the studies done recently. ${ }^{10,11}$ Moreover recent studies have also shown the leading cause of CRBSI to be gram negative bacilli. ${ }^{12}$ Acenitobacter baumannii was the most common organism isolated $(29 \%)$ which is in contrast with the similar studies done in the past, ${ }^{6-11}$ where some of the studies showed Staph. aureus, CONS and Pseudomonas aeruginosa as the commonest organism colonizing CVC. This may be due to emergence of Acentiobacter species as common colonizer in hospitalized patients in recent years. ${ }^{13}$ According to various literature common organism colonizing CVC and associated with infections are CONS, Staph aureus, Candida spp and gram negative bacilli. ${ }^{14}$ Our study also confirmed these findings.

In this study overall isolates were mostly sensitive to chloramphenicol. However, routinely used antibiotics, like Gentamicin, Amikacin and Ceftriaxone are mostly resistant. Our study also showed decrease in sensitivity to Imepenem and Piperacillin-Tazobactum, which are commonly used in ICU settings. This shows the changing pattern in antibiotic sensitivity.

Our study showed $100 \%$ efficacy to Vancomycin and Lenezolid, which are used, only in gram positive organism and Colistin.

\section{CONCLUSION}

In conclusion, we report a significant shift in colonizers of central venous catheter towards predominance of Gram negative bacilli, so empirical treatment must to prevent CRBSI must address their increasing prevalence. We suggest that empirical antibiotic selection should be based on knowledge of the local prevalence of bacteria and antibiotic sensitivity pattern rather than on universal or even national guidelines.

\section{REFERENCES}

1. O'Grady NP, Alexander M, Dellinger EP, Gerberding JL, Heard SO, Maki DG, et al. Guidelines for the prevention of intravascular catheter-related infections. Infect Control Hosp Epidemiol. 2002;23:759-69. Crossref

2. Wenzel RP, Edmond MB. The impact of hospital-acquired bloodstream infections. Emerg Infect Dis. 2001;7:174-7. Crossref

3. Preventing bloodstream infections from central line venous catheters Crossref

4. Slobbe L, El Barzouhi A, Boersma E, Rijnders BJ. Comparison of the roll plate method to the sonication method to diagnose catheter colonization and bacteremia in patients with long-term tunnelled catheters: a randomized prospective study. J. Clin. Microbiol
2009;47:885-8. Crossref

5. Winn WC, Koneman EW. Koneman's color atlas and textbook of diagnostic microbiology. Philadelphia: Lippincott Williams \& Wilkins; 2006.

6. Meadows C, Creagh-Brown B, Nia T, Bonnici K, Finney S. Definition of catheter-related bloodstream infection as a quality improvement measure in intensive care. Critical Care. 2009;13:191. Crossref

7. Tullu MS, Deshmukh CT, Baveja SM. Bacterial profile and antimicrobial susceptibility pattern in catheter related nosocomial infections. Postgrad. Med. J 1998;44:7-13.

8. Karpel E, Kunsdorf-Wnuk A, Musiol E, Skorupa A, Arct-Danielak $\mathrm{D}$, Jarosz U. [Cathether related blood stream infection in ICU patients with prolonged central venous catheterisation--cause and prevention]. Polski merkuriusz lekarski : organ Polskiego Towarzystwa Lekarskiego. 2006;21:211-7.

9. Pérez-Granda MJ, Guembe M, Cruces R, Barrio JM, Bouza E. Assessment of central venous catheter colonization using surveillance culture of withdrawn connectors and insertion site skin. Critical Care. 2016;20:32. Crossref

10. Hodzic S, Tihic N, Smajic J, Omerbegovic M, Sljivic M. Frequency of the central venous catheter colonization in surgical intensive care unit. Medicinski arhiv. 2010;64:245-7. Crossref

11. Naveen, G., G. Latha and Nagraj, C. Bacteriological Study of Central Line Associated Blood Stream Infection at a Tertiary Care Hospital. Int.J.Curr.Microbiol.App Sci 2016;5:645-9. Crossref

12. Braun E, Hussein K, Geffen Y, Rabino G, Bar-Lavie Y, Paul M. Predominance of Gram-negative bacilli among patients with catheterrelated bloodstream infections. Clin Microbiol Infect 2014;20:O6279. Crossref

13. Fishbain J, Peleg AY. Treatment of Acinetobacter infections. Clinical infectious diseases. Clin Infect Dis. 2010;51:79-84. Crossref

14. Pascual A. Pathogenesis of catheter-related infections: lessons for new designs. Clin Microbiol Infect 2002;8:256-64. Crossref 